\title{
The Research of Electric Teaching Model Based on "Innovative Talent Training Goals"
}

\author{
Yixin Yan ${ }^{1, a,{ }^{*}, \text { Shaoliang Meng }}{ }^{1, b}$ and Jianxin Gai ${ }^{1, c}$ \\ ${ }^{1}$ Harbin University of Science and Technology, Harbin, Heilongjiang, China \\ ashiyu_wang@126.com, ${ }^{b} \mathrm{msl39@163.com,}{ }^{\mathrm{a}} \mathrm{gj}$ ×800608@126.com
}

${ }^{*}$ Corresponding author

\begin{abstract}
The training objectives based on modern education is to explore the reform of the traditional teaching model and to design a new model based on "innovative talents training goals" for electric teaching. The new electric teaching model includes updating teaching resources, promoting student deeply involved electric professional courses, redesigning the process of teaching, exploring the new ways of thinking, designing examples for analyzing and presenting management measures.
\end{abstract}

Keywords: Innovative talent training, Electric curriculum, Teaching mode.

\section{基于 “创新型人才培养目标” 的电类专业课程教学模式研究 \\ 颜䝠欣 ${ }^{1, ~ a, ~}{ }^{*}$, 孟绍良 ${ }^{1, b}$, 盖建新 ${ }^{1, c}$ \\ ${ }^{1}$ 哈尔滨理工大学测控技术与通信工程学院, 哈尔滨, 黑龙江, 中国 \\ ashiyu_wang@126.com, bmsl39@163.com, ojx800608@126.com \\ 通讯作者}

中文摘要. 本研究基于现代教育培养目标, 以探讨改革我国传统教学模式为目的, 设计 了基于 “创新型人才培养目标” 的电类专业 课程教学模式: 更新教学资源、促进学生深 度参与、重新设计教学过程和促进思维方式 转变, 然后通过案例进行了具体设计并提出 了相关配套管理措施。

关键词: 创新型人才培养; 电类专业课程; 教学模式

\section{1. 引言}

多样化的创新型人才培养模式是创新 型人才培养体系是否真正建立的核心。要实 现由培养常规人才为主向培养创新型人才 为主转变, 需实现由封闭式独立培养向开放 式联合培养的转变。教师应努力在教学实践 中, 寻求适合本学科特点的有效教学方法, 将创新渗透到教学的每个环节, 从而促进学 生动手能力的提高与创造性思维的养成。也 需要将创新创业教育理念融入本科人才培 养方案, 创新创业教育必修8学分融入专业 人才培养总学分, 创新创业课程融入专业课 
程体系, 创新创业实践融入专业实践教学, 创新创业保障措施融入人才培养保障体系, 潜在创业者培养融入就业教育与指导。本文 为此具体探讨了基于 “创新型人才培养目 标”的电类专业课程教学模式, 现报告如下。

\section{2. 创新型人才培养目标的内涵与要求}

\section{1 高技术人才培养模式}

我们要对接多种教育模式, 部分与地区 支柱产业联系紧密的学院, 开展职业技术教 育, 培养高技术专门人才, 探索一种在电类 专业课程中开展技术教育的新模式。要积极 结合电力工程应用与研究, 确立培养具备较 强电力实践能力、电力设计及研究能力、电 力创新能力、电力管理和竞争能力的优秀电 力工程师人才培养标准, 通过跨学科交叉研 究模式与产学研联合办学模式相结合, 形成 创新型电力工程师的培养模式。

\section{2 校企合作育人模式}

与合作企业建立紧密联系，积极探索 “嵌入式”、“订制式”、“整体合作式”、 “校地合作式”、“分段式” 等人才培养模 式, 共同研制专业人才培养方案、人才培养 质量标准, 共同设计课程, 制定课程标准, 开发教材, 为学生提供实践操作条件, 并选 派专业人员到校兼课, 构建起多样化的校企 深度合作育人模式。软件工程学院以 “夯双 基，强两项，建双控，提两能”目标为核心， 以“校企联动” 无缝对接实训平台为支撑, 以 “三维立体” 创新实验教学体系为载体, 形成 “学历教育+工程训练” 的工程化人才 培养模式。

\section{3 创新创业教育模式}

将创新创业教育融入人才培养体系, 贯 穿人才培养全过程, 坚持普及与提高相结合 原则，建立“课程、培训、实践、服务”四 位一体的创新创业教育体系, 开发校本课 程、校本教材, 建设专兼结合的教学团队, 完善孵化基地和服务体系, 开展创业先锋班 试点, 形成富有特色的创新创业教育模式。 学校可以成立创新创业教育与指导中心, 建 立了大学生创业指导专家库, 重点围绕创新 创业课程建设、模拟实验室建设、实践基地
建设、创新创业教学与指导等开展工作; 将 创新创业纳入人才培养方案, 实现创业教育 进课堂, 实施创新学分替代制, 提升了学生 创新创业能力; 开设大学生 “创业先锋班”, 设计 “创业能力、创业实验和创业实务” 三 大模块对学生创业进行系统培训。

\section{3. 基于 “创新型人才培养目标” 的电类专 业课程教学的模式}

\section{1 更新教学资源}

电类专业课程理念下, 教材是一种教学 资源, 但不是唯一资源。教师可以根据教学 目标的要求与学生的实际情况, 在整合多种 资源的基础上对教材内容进行再创造, 如删 减、增补、拓展与重组等。在教学实践中, 我经常对教材内容进行拓展和增补, 尤其注 重通过具体问题, 在与学生互动的基础上补 充方法性、规律性的内容, 从而促进学生学 习能力的提升。

\section{2 促进学生深度参与}

课堂教学改革中, “激励学生主动参与 教学过程” 是一个重点。在教学中教师要为 学生参与教学提供条件。学生参与的形式多 种多样, 如自主学习、动手操作、互帮互学、 交流讨论、合作探究、展示汇报、质疑答辩 等。在各种学习活动中, 教师应努力找到适 当的方法促成学生思维的深度参与, 而不是 追求课堂的表面热闹。比如, 在电学教学中, 我发现学生对 “实物图”与 “电路图”之间 的相互转换存在一定思维障碍。经分析有四 个方面原因：第一，学生对电源、开关、电 阻或滑动变阻器、灯泡、电流表及电压表等 电路元件实物不熟悉, 特别是对电流流过元 件接线柱之后再经其内部的流向不清楚。第 二, 电路中实物的位置与电路图中相应元件 符号的位置不对应。第三, 不能将实物图中 导线的 “曲线走向” 与电路图中导线的 “规 则走向” 统一起来。第四, 实物图中导线有 长有短, 甚至是一个点, 不能与电路图中规 则的导线对应起来。从思维角度讲, 从 “实 物图” 到 “电路图” 是一个由具体到抽象的 思维过程。在相关教学中, 我让学生在小组 合作中群策群力, 讨论分析, 然后就疑难点 进行现场剖析。学生清楚实物图中电流的流 
向及各个元件的连接方式之后, 在脑海中能 够 “抽象” 出一个 “电流流向图”, 再按照 画图 “方便” 的要求画出 “电路图”。由于 学生思维的深度参与, 教学的难点顺利突 破。

\section{3 重新设计教学过程}

从学习的深层意义上讲, 学生的学习过 程是一个不断提出问题、分析问题和解决问 题的过程。问题是思维的起点, 有了问题才 能进一步研究, 学习活动才会更加深入。因 此, 教师需强化问题意识, 善于将教材内容 进行问题化处理, 即将教材内容设计成一个 个问题, 然后让学生通过自主学习或者合作 探究去解决。在 “串联和并联” 的教学中, 我将教材内容设计成四个逐步递进的问题。 问题一: 电路是由什么组成的? 请你画出一 个 “最简单电路” 的电路图。问题二: 给你 一个电源、两个小灯泡、一个开关和若干导 线, 如何连接使这两戞灯都发光? 会有几种 不同的连接方式? 试着接通电路。问题三: 试着连接一个串联电路并对开关的作用进 行探究。问题四: 试着连接一个并联电路并 对干路和支路中开关的作用进行探究。这四 个问题的难度逐步升级, 学生通过合作一一 解决, 整个探究过程兴趣盎然。学生在分析 问题、解决问题中收获了知识, 也享受到了 学习的快乐。

\section{4 促进思维方式转变}

思维能力是智力的核心。“让学生 动起来” 的核心是 “让思维动起来”, 这是 将课改引向深入的必由之路。因此, 教师要 多为学生创造思考的机会, 大力强化学生的 思维训练。课堂教学过程中, 不但要给学生 思维的机会, 更要注重检验学生思维的效 果。我在教学中通过让学生 “说出来” 检验 学生思维的开阔性、流畅性、逻辑性、完整 性、独立性、深刻性及创造性等。

\section{4. 基于 “创新型人才培养目标” 的电类专 业课程教学模式的设计-电力虚拟教学技术}

\section{1 教学模式}

在虚拟逼真的实验环境中, 电类专业课 程以问题-探究型教学模式为核心, 通过文
字、图片、动画、视频、课件等方法手段把 实验内容或实验现象以一个个问题的形式 呈现出来, 学生在分析问题的基础上, 根据 自己个人的历史知识经验和个人情感等因 素, 充分发挥自己主动性和积极性, 从问题 出发, 有目的、有选择的对教学资源库中的 教学资源进行搜集、分析、整理、组合，从 而建立自己的学习资源库; 然后, 学资料与 信息设计出解决问题的方法或方案, 并在实 验室进行相应的实验验证获得相关的数据 或答案, 以验证自己的方法或方案是否正 确, 直到解决问题为止。

\section{2 教学环境的创设}

\subsection{1 硬件环境}

数字化硬件环境建设主要是建设能支 持信息技术应用于电类专业课程的教学过 程中的硬件设施, 包括各种教学媒体, 校园 服务设施，各种配套的教学、管理、实验实 施等。首先在电力工程实验室的每个实验工 作台配上一台多媒体计算机, 并把每台计算 机用网线连接起来形成实验室LAN, 然后与 校园网相连, 实验室LAN通过校园网与网络 连接起来。在网络的环境下, 处于网络上的 每台计算机之间是连通的, 可以相互间进行 通

信与访问。

\subsection{2 软件环境}

在硬件环境的基础上，利用多媒体技 术、互联网技术、虚拟仿真技术等在校园网 上建立具有开放性的虚拟电力工程平台。此 虚拟电力工程平台不但能实现教学管理和 电子实验, 而且能够给学生提供多种学习和 探索的工具、交流渠道、信息资源等。

\section{3 教学内容的重构}

传统的电类专业课程教学所使用的教 材及其组织形式、内容分类及呈现方式已经 不能满足信息技术与电类专业课程整合的 教学要求, 因此, 针对信息技术与电类专业 课程整合的教学特点, 在认知学习理论及建 构主义学习理论指导下, 对实验教学的内 容、组织形式、呈现方式进行重构, 以利于 在电类专业课程的教学过程的每个环节充 分信息技术的优势和特点, 提高电类专业课 程的教学效率和质量。 


\section{4 实验内容}

(1)组织形式: 电类专业课程教学内容 的组织应该遵循充分发挥学生主动性, 以学 生为中心的原则进行, 教学内容以知识点的 形式进行组织, 每个知识点以问题或任务的 形式呈现, 将知识点所需要的各种资料及建 议性的学习方法等信息附加在其后。这些内 容的有机组合能促使学生将原有的知识与 将要学习的内容建立横向和纵向的联系, 有 利于学生知识的建构, 有利于学生在不同的 情境下去应用他们所学的知识。(2)实验类 型: 为了充分发挥学生的主动性, 培养学生 的综合实验能力, 更好的适应信息技术与电 类专业课程整合的教学模式, 把电力工程分 为两种类型: 基础实验和设计实验。基础实 验的目的是巩固学生的专业理论和知识基 础, 训练学生的基本技能和基本专业素质, 为综合实验打好基础。设计实验的目的是提 高学生的专业兴趣, 培养和训练学生的自习 能力与解决问题的能力, 增强学生的专业素 质和职业能力, 培养学生的团队协作精神, 主动创新能力, 培养信息的搜集、分析、整 理、应用等信息素养。

\section{5 实验方法}

实验方法分为真实实验和虚拟仿真实 验。真实实验是在以信息技术为基础的虚拟 电力工程平台的电力工程中, 以学生为实验 教学主体, 从解决 “问题” 为出发, 学生按 照自己为解决问题设计的方案、设想或猜测 等设计出的实验方案, 在真实的实验环境 中, 使用真实的实验仪器设备和电子原器件 等建立实验电路进行实验, 以验证方案的设 计、设想或猜测, 最终达到解决问题的目的。 真虚拟仿真实验是在以信息技术为基础的 虚拟电力工程平台的电力工程中, 以学生为 实验教学主体, 从解决 “问题” 为出发, 学 生按照自己为解决问题设计的方案、设想或 猜测等设计出的实验方案, 在网络环境下, 由虚拟仿真技术生成的一类适于进行虚拟 实验的实验系统中，包括相应的实验环境、 有关的实验仪器设备、实验对象和实验信息 资源, 学生利用相应的虚拟实验资源建立实 验电路进行实验, 以验证方案的设计、设想 或猜测, 最终达到解决问题的目的。由于虚
拟仿真实验学生只要在虚拟仿真实验系统 中利用系统提供的实验资源建立实验电路 即可进行实验, 不受现实器件和仪器设备的 约束, 省去了器件的购买、电路的制作与调 试等时间, 不必担心器件与仪器设备的损 坏, 缩短了实验周期和降低实验费用和损 耗, 大大提高了电力工程的效率, 而且仿真 技术允许实验者按照要求设计自己的元器 件, 使仿真实验能实现与最新技术与器件同 步, 是现代电力工程最常用的一种实验方 式, 是各种电子设计设计方案、电路可行性、 合理性等分析验证的主要方式。

\section{6 教学的调查与反馈}

教师要定期对学生就电类专业课程教 学相关内容进行问卷调查, 以了解学生的学 习情况和教学过程, 了解电类专业课程教学 的优点与不足, 为电类专业课程的教学改进 提供参考和有效的数据。教师也可以随机的 抽取部分学生, 就学生上交的实验报告或电 子产品设计的相关内容进行提问, 以确认和 了解学生的学习情况和效果。以便进一步的 改进电类专业课程的教学。

\section{5. 基于 “创新型人才培养目标” 的电类专 业课程教学模式的配套管理措施}

\section{1 以精细化管理提升办学水平}

在 “精” 字上做文章, 在 “细” 字上下 功夫, 学校领导班子密切配合, 分管校领导 各负其责, 将总体责任分解到各个部门, 部 门再落实到个人, 通过责任分解, 层层把关, 目标明确。并将柔性管理 “沟通、共享、发 展” 渗透到管理之全过程中, 着力营造良好 的工作环境, 凝聚人心, 提升人气, 鼓舞士 气。形成风正气顺、和谐共事、精诚团结、 其乐融融的工作环境。

\section{2 加强师资培训}

建议学校出台推进青年教师 “博士化、 国际化、工程化” 的若干规定, 利用校企合 作平台, 搭建青年教师工程实践平台。比如 某某学校每年安排10余名青年博士教师在 正式上岗前，到企业接受为期 6 个月的 “工 程化” 实践培训。组织广大青年教师学习阅 读《教师的师德修养》等书籍, 促进全体教 
师提升师德修养。创新教育教学方式, 增加 教学的趣味性; 邀请地区教育专家开展专题 培训, 组织青年教职人员进行为期 3 天的培 训, 及时更新教师的教学理念。

\section{3 行业需求纳入培养方案}

学校根据用人单位提出的“人才标准”, 按照用人单位的人才规格、技能水平等需求 进行培养。校企双方协商制定教学计划, 根 据企业岗位设计课程内容和技能操作, 这种 培养模式实现学生入学、培养与就业的高度 统一, 就业成功率高。比如很多企业在某某 学校专门配了班主任, 人事部门不定期组织 开展企业文化、职业生涯规划等讲座, 介绍 企业各个岗位的职责和发展空间。也可以 针对学校电子电器等专业实验实习课较多 的实际, 教学采用教师在实验室、实训室边 讲边示范, 学生边听边亲自动手做的教学方 法, 一方面解决了教、练分离和理论、实践 两张皮的问题, 另一方面增强了学生学习的 主动性和趣味性, 使师生、生生之间在轻松 愉快的交流、互动中把所学技能掌握得更准 确、牢固。也可以实行 “工学交替” 培养模 式, “工学交替” 的教学模式是让学生在 “练 中学”, 即先练后学, 学后再练, 学生在练 习中把上岗操作的规程形成理论, 然后再通 过学习理论强化自身的操作技能, 使学生练 后知惑, 学然后知不足, “工学交替” 培养 模式增强了学生岗位职业水平。

\section{6. 结束语}

基于 “创新型人才培养目标” 的电类专 业课程教学模式大大提升了学校教学的质
量, 培养出的学生就业适应岗位快, 并能极 大提高电力教学效果、培养学生多方面能力 的教学模式。

\section{References}

[1] 童艳燕.对技工学校电类课程教学创新 的探讨 [J].管理学家,2010 年 10 期.

[2] 李勇.创新项目教学在电类课程中的应 用 $[\mathrm{J}]$.广东教育(职教版),2013 年 6 期.

[3] 覃洪英, 张正炳.非电类数字电路课程创 新教学研究[J].中国现代教育装备, 2009 年 7 期.

[4] 周来秀, 杨冰.电路课程立体化教案的现 状与创新[J].中国科技信息， 2010 年 11 期.

[5] 王瑛, 李广德.职业院校电类课程教学方 法的创新与探索-项目化、趣味性的教 学方法 [J].空中英语教室(新教师教学), 2011 年 9 期.

[6] 韦东梅, 吴杰康, 李泽.传统"电路理论" 课程教研室设置现状及创新教学实践 [J].中国电力教育， 2009 年 12 期.

[7] 张晓琴.高职电力工程系列课程创新教 学改革与实践 $[\mathrm{J}]$.消费电子，2012 年 9 期.

[8] 黄世忠. 应注重培养科学的复习方法 $[\mathrm{J}]$. 广西教育，2009，(6) : 64-65.

[9] 何学坤. 实践教学的探索与思考 $[\mathrm{J}]$. 职 业教育研究，2006，(3)：141-142. 